DOI: https://doi.org/10.24127/ajpm.v9i4.3049

\title{
META ANALISIS: PENGARUH PROBLEM-BASED LEARNING TERHADAP KEMAMPUAN LITERASI MATEMATIS SISWA DI INDONESIA TUJUH TAHUN TERAKHIR
}

\author{
Muhammad Fachri B. Paloloang1, Dadang Juandi², Maximus Tamur 3*, \\ Baharuddin Paloloang ${ }^{*}$, Angela M G Adem ${ }^{*}$ \\ ${ }^{1,2}$ Universitas Pendidikan Indonesia, Bandung, Indonesia \\ ${ }^{3 *}$ Universitas Katolik Indonesia Santu Paulus Ruteng, Indonesia \\ ${ }^{4 *}$ Universitas Tadulako, Palu, Indonesia \\ ${ }^{5 *}$ Teachers College of Columbia University: New York, NY, US \\ *Corresponding author \\ E-mail:_fachripaloloang@gmail.com ${ }^{1)}$ \\ dadang.juandi@upi.edu ${ }^{2)}$ \\ maximustamur@unikastpaulus.ac.id${ }^{3 *)}$ \\ baharuddinpaloloang@gmail.com ${ }^{4 *}$ \\ aga2146@tc.columbia.edu ${ }^{5^{*}}$
}

Received 18 August 2020; Received in revised form 16 November 2020 Accepted 02 December 2020

\begin{abstract}
Abstrak
Hingga saat ini ratusan kajian tentang kemampaun literasi matematis siswa telah disajikan dalam bentuk literatur yang didukung oleh penggunaan model Problem Based Learning (PBL). Dalam literatur terdapat banyak laporan dengan temuan yang bervariasi. Studi meta-analisis ini dilakukan untuk memeriksa efek keseluruhan penggunaan model PBL terhadap kemampuan literasi matematis siswa dan mendeteksi tingkat variasi antar studi. Database ERIC, SAGE, SpringerLink, dan Google Cendekia diperiksa untuk mencapai penelitian yang relevan dalam lingkup penelitian. Dengan memasukkan kata kunci yang telah ditentukan ke dalam database ini, ditemukan 112 artikel yang diterbitkan antara tahun 2013 dan 2020 diperiksa untuk tujuan penelitian. Sesuai kriteria inklusi, 14 artikel yang memenuhi kelayakan untuk dianalisis. Alat bantu analisis menggunakan software Comprehensive Meta-Analysis (CMA), dan indeks ukuran efek dari persamaan Hedges-g yang diperoleh ditentukan berdasarkan pada estimasi model efekacak. Hasil penelitian ditemukan ukuran efek secara keseluruhan dari penerapan PBL terhadap kemampuan literasi matematis siswa adalah 0.830 dengan standar error sebesar 0.142 . Temuan ini mengindikasikan bahwa penerapan PBL di Indonesia cukup efektif karena memeliki efek positif yang tinggi dalam meningkatkan kemampuan literasi matematis siswa. Analisis terhadap tingkat variasi studi dilakukan dengan mempertimbangkan empat variable moderator, menghasilkan perbedaan yang signifikan dalam hal sumber publikasi penelitian $(\mathrm{Q}=7,571 ; \mathrm{p}<0,05)$, dan perbedaan jenjang Pendidikan $(\mathrm{Q}=16,571 ; \mathrm{p}<0,05)$. Ditemukan bahwa variable tahun penelitian $(\mathrm{Q}=5,962 ; \mathrm{p}>0,05)$, dan ukuran sampel $(\mathrm{Q}=0,277 ; \mathrm{p}>0,05)$ tidak mengubah ukuran efek penggunaan PBL terhadap kemampuan literasi matematis siswa. Temuan ini menandakan bahwa model PBL lebih efektif diterapkan pada jenjang pendidikan yang lebih tinggi. Fakta ini berkontribusi literatur sebagai pertimbangan dalam ilmplementasi PBL terhadap kemampuan literasi matematis dimasa depan.
\end{abstract}

Kata kunci: Literasi matematika; meta-analisis; moderator, problem based learning.

\begin{abstract}
Until now, hundreds of studies on students' mathematical literacy skills have been presented in the form of literature supported by the use of the Problem Based Learning (PBL) model. In the literature, there are many reports with varying findings. This meta-analysis study was conducted to examine the overall effect of using the PBL model on students' mathematical literacy abilities and detect the degree of variation between studies. The ERIC, SAGE, SpringerLink, and Google Scholar databases were examined to achieve research relevant to the study's scope. Entering predetermined keywords into this database found 112 articles published between 2013 and 2020 were analyzed for research purposes. As per the inclusion
\end{abstract}


DOI: https://doi.org/10.24127/ajpm.v9i4.3049

criteria, 14 articles were eligible for analysis. The analysis tool uses Comprehensive Meta-Analysis (CMA) software, and the effect size index of the Hedges-g equation obtained is determined based on the random-effect model estimation. The results showed that the overall effect size of the application of PBL on students' mathematical literacy abilities was 0.830 , with a standard error of 0.142. These findings indicate that the application of PBL in Indonesia is quite effective because it has a largely positive effect on improving students' mathematical literacy skills. Analysis of the level of study variation was carried out by considering four moderator variables, resulting in significant differences in terms of sources of research publications $(Q=7.571 ; p<0.05)$ and differences in education levels $(Q=16.571 ; p<0.05)$. It was found that the variables of the study year $(Q=5.962 ; p>0.05)$ and the sample size $(Q=0.277$; $p$ > $0.05)$ did not change the size of the effect of PBL use on students' mathematical literacy abilities. These findings indicate that the PBL model is more effective at higher education levels. This fact contributes to the literature as a consideration in implementing PBL for future mathematical literacy skills.

Keywords: Mathematical literacy; meta-analysis; moderator; problem-based learning.

This is an open access article under the Creative Commons Attribution 4.0 International License

\section{PENDAHULUAN}

Orientasi pendidikan saat ini adalah agar siswa memperoleh pengetahuan dan kompetensi yang memenuhi kebutuhan masyarakat modern (Bolstad, 2020). Sejalan dengan itu maka kemampuan literasi matematis diperlukan untuk memproses, mengkomunikasikan, dan menafsirkan informasi matematika dalam berbagai konteks agar dapat bertahan dalam masyarakat modern saat ini (Genc \& Erbas, 2019; OECD, 2019; Pradana et al., 2020). Jelas bahwa penguasaan terhadap kemampuan literasi matematis memiliki implikasi yang luas untuk siswa.

Kemampuan literasi matematis siswa dapat ditingkatkan dengan menggunakan model pembelajaran yang sesuai (Freeman-Green et al., 2015; Tamur, 2017). Terkait dengan itu, Bolstad, (2020) menyarankan bahwa pembelajaran yang mengatur siswa untuk bekerja dengan masalah terbuka dengan konteks dunia nyata seperti pemecahan masalah matematika dapat mengembangkan literasi matematika. Salah satu model pembelajaran yang memenuhi saran tersebut adalah PBL. PBL melibatkan siswa dalam keterampilan berpikir, pemecahan masalah, komunikasi, kerja kelompok, dan berbagi informasi dengan orang lain (Akinoğlu \& Tandoğan, 2007).

Penggunaan model PBL dianggap mempengaruhi kemampuan literasi matematis siswa. Namun, penelitian sebelumnya yang menyelidiki asumsi teoretis ini membuahkan hasil yang beragam. Penelitian yang dilakukan oleh (Istiandaru et al., 2015; Priyonggo et al., 2019; Sriwahyuni et al., 2018) telah menunjukkan bahwa penggunaan PBL efektif dalam meningkatkan kemampuan literasi matematis siswa. Sementara, (Astuti, 2020; Aula et al., 2019; Dewi \& Listyani, 2018; Wicaksono \& Agustyaningrum, 2018) telah mengidentifikasi bahwa kemampuan literasi matematis siswa yang diajarkan menggunakan model PBL tidak lebih baik dari pada kemampuan literasi matematis siswa yang diajarkan menggunakan pendekatan konvensional.

Studi yang berbeda pada topik yang sama terkadang memberikan hasil hasil yang bervariasi bahkan kontradiktif dan mengakibatkan bahwa penarikan kesimpulan tentang pertanyaan penelitian dapat bersifat subjektif (Franzen, 2020; Tamur, Juandi, \& Kusumah, 2020). Dengan 
DOI: https://doi.org/10.24127/ajpm.v9i4.3049

demikian, perlu mengintegrasikan temuan kuantitatif sehingga memberikan kesimpulan yang akurat dan berguna untuk penetapan kebijakan (Higgins \& Katsipataki, 2015). Akibatnya, studi meta-analisis diperlukan dengan tujuan mengintegrasikan dan menafsirkan temuan untuk memperoleh kesimpulan yang mendalam dan meyakinkan (Schmidt \& Hunter, 2015; Tamur \& Juandi, 2020).

Meta-analisis menghitung ukuran efek dan menggabungkannya dalam rumus obyektif, sehingga meningkatkan kemungkinan bahwa pembaca yang berbeda akan datang ke kesimpulan yang sama (Schmidt \& Hunter, 2015). Namun, hingga saat ini dalam literatur belum ditemukan studi meta-analisis khusus yang mempertanyakan pengaruh PBL terhadap kemampuan literasi matematis siswa. Sementara ada kebutuhan bahwa pendidik memerlukan informasi yang akurat untuk memutuskan di bawah kondisi apa penggunaan PBL akan efektif dalam meningkatkan kemampuan literasi matematis siswa.

Penelitian meta-analisis yang mempertanyaan efek PBL pada kemampuan akademik siswa secara umum telah dilakukan oleh Demirel \& Dağyar (2016), Dochy et al. (2003), Gijbels et al. (2005), Rosli et al. (2014), dan Qin et al. (2016). Mereka menemukan bahwa ukuran sampel penelitian primer mempengaruhi ukuran efek studi, dan jenjang pendidikan tidak mengubah ukuran efek studi. Namun temuan tersebut masih bersifat sementara karena kriteria inklusi dan lingkup pencarian terbatas. Di Indonedia telah dilakukan studi metaanalisis tentang efek PBL pada kemampuan berpikir kritis dan kreatif siswa (Anugraheni, 2018; Yanto et al.,
2019). Namun, mereka tidak melibatkan analisis statistik yang merupakan esensi dari studi meta-analisis.

Selanjutnya Asror (2016) telah melakukan meta-analisis efek PBL dan melibatkan analisis statistik tetapi tidak memperlihatkan estimasi model efek acak atau model efek tetap yang seharusnya dipilih berdasarkan uji homogenitas. Akibatnya efek yang dilaporkan cendrung mengalami bias. Penggunaan model estimasi dan analisis terhadap bias publikasi telah dilakukan dalam meta-analisis terbaru oleh Tamur, Juandi, \& Adem (2020), namun penelitian tersebut menganalisis efek penerapan Pendidikan Matematika Realistik Indonesia (PMRI) terhadap kemampuan literasi matematis siswa.

Penelitian ini memperluas dan melengkapi penelitian sebelumnya yang berfokus pada menentukan efek keseluruhan PBL pada kemampuan literasi matematis siswa, dan meneliti alasan adanya variasi ukuran efek antar studi primer dengan menganalisis hubungan variabel moderator yang teridentifikasi yaitu tahun penelitian, perbedaan jenjang pendidikan, durasi perlakuan, dan sumber publikasi. Temuan penelitian ini memberikan informasi yang akurat kepada pendidik dalam mengimplementasikan PBL di masa depan. Penjelasan tersebut menjustifikasi pentingnya melakukan studi meta-analisis tentang efek PBL pada kemampuan literasi matematis siswa di Indonesia tujuh tahun terahir.

\section{METODE PENELITIAN}

Penelitian ini menggunakan metode meta-analisis dengan mereview beberapa artikel di jurnal nasional dan internasional. Studi primer yang dianalisis, berkaitan dengan pengaruh penerapan PBL terhadap kemampuan literasi matematis siswa. Secara umum 
Borenstein et al. (2009) menjelaskan tahapan dalam meta-analisis yaitu; pertama, ditentukan kriteria inklusi untuk studi yang dianalisis. Kedua, prosedur untuk mengumpul data empiris dan pengkodean variabel studi akan dijelaskan. Ketiga, teknik statistik untuk dijelaskan. Pekerjaan ini juga mengikuti langkah-langkah ini.

\section{Kriteria Inklusi}

Semua artikel studi dalam pencarian awal diperiksa dan dinilai untuk dimasukkan dalam meta-analisis menggunakan kriteria inklusi berikut:

1. Rentang tahun publikasi 2013 hingga 2020.

2. Artikel yang melibatkan penulis Indonesia dan dipublikasikan di jurnal atau prosiding internasional, nasional, atau yang telah diindeks SINTA.

3. Artikel penelitian memiliki minimal satu kelas eksperimen dengan model PBL dan yang lainnya adalah kelas konvensional atau model lain sebagai kelas kontrol.

4. Artikel studi melaporkan cukup data untuk transformasi ukuran efek.

\section{Pengumpulan Data}

Data empiris yang diperoleh dari database ERIC, SAGE, SpringerLink, dan Google Cendekia diperiksa untuk mencapai penelitian yang relevan dalam lingkup penelitian dengan kata kunci, "problem-based learning" dan "mathematical literacy". Prosedur ini menghasilkan 112 artikel yang diterbitkan antara tahun 2013 dan 2020 diperiksa untuk tujuan penelitian. Selanjutnya instrumen meta-analisis yaitu berupa lembar pengkodean variabel telah dikembangkan untuk mengidentifikasi artikel yang telah dikumpulkan. Dua orang dilibatkan sebagai pengkode menggunakan instrumen penelitian. Sesuai kriteria inklusi, hanya 14 artikel yang memenuhi kelayakan untuk dianalisis dan diperoleh dari database Google Cendekia. Tabel 1 menjelaskan informasi tentang studi primer yang telah diterbitkan oleh berbagai jurnal.

Tabel 1. Daftar jurnal yang telah menerbitkan tudi PBL pada kemampuan literasi matematis.

\begin{tabular}{|c|c|c|}
\hline No & Nama Jurnal & URL \\
\hline 1 & Edumatica & $\begin{array}{l}\text { https://online- } \\
\text { journal.unja.ac.id/ } \\
\text { edumatica }\end{array}$ \\
\hline 2 & $\begin{array}{l}\text { Unnes Journal } \\
\text { of } \\
\text { Mathematics } \\
\text { Education } \\
\text { (UJME) }\end{array}$ & $\frac{\underline{\text { https://journal.un }}}{\text { nes.ac.id/sju/inde }}$ \\
\hline 3 & $\begin{array}{l}\text { UNION: } \\
\text { Jurnal Ilmiah } \\
\text { Pendidikan } \\
\text { Matematika }\end{array}$ & $\begin{array}{l}\text { http://jurnal.ustjo } \\
\text { gja.ac.id/index.ph } \\
\text { p/union/index }\end{array}$ \\
\hline 4 & $\begin{array}{l}\text { Integral } \\
\text { Pendidikan } \\
\text { Matematika }\end{array}$ & $\begin{array}{l}\text { https://e- } \\
\text { journal.umc.ac.id/ } \\
\text { index.php/JNR } \\
\text { https://journal.un }\end{array}$ \\
\hline 5 & PRISMA & $\begin{array}{l}\text { nes.ac.id/sju/inde } \\
\text { x.php/prisma/ }\end{array}$ \\
\hline 6 & $\begin{array}{l}\text { Unnes Journal } \\
\text { of } \\
\text { Mathematics } \\
\text { Education } \\
\text { Research } \\
\text { (UJMER) }\end{array}$ & $\frac{\frac{\text { http://journal.unn }}{\text { es.ac.id/sju/index. }}}{\text { php/ujmer }}$ \\
\hline 7 & Alphamath & $\begin{array}{l}\text { http://jurnalnasio } \\
\text { nal.ump.ac.id/ind } \\
\text { ex.php/alphamath }\end{array}$ \\
\hline 8 & $\begin{array}{l}\text { E-Journal } \\
\text { Mahasiswa } \\
\text { UNY }\end{array}$ & $\begin{array}{l}\text { http://journal.stud } \\
\text { ent.uny.ac.id/ojs/i } \\
\text { ndex.php/math }\end{array}$ \\
\hline
\end{tabular}

Sebagaimana dijelaskan pada Tabel 1, maka daftar jurnal yang mempublikasikan kajian PBL tentang kemampuan literasi matematika adalah 8. Mengikuti kriteria inklusi maka penelitian yang digunakan dalam analisis adalah 14 artikel. Namun, 
DOI: https://doi.org/10.24127/ajpm.v9i4.3049

karena beberapa studi menguji lebih dari satu perbandingan, ada 16 ukuran efek yang dianalisis. Tabel 2 menunjukkan informasi tentang penelitian ini.

Tabel 2. Informasi tentang Penelitian

\begin{tabular}{cllc}
\hline No & $\begin{array}{c}\text { Variabel } \\
\text { Mediator }\end{array}$ & \multicolumn{1}{c}{ Kelompok } & $\begin{array}{c}\text { frekuen } \\
\text { si }\end{array}$ \\
\hline \multirow{4}{*}{1} & & $2013-2014$ & 4 \\
1 & Tahun & $2015-2016$ & 2 \\
& Penelitian & $2017-2018$ & 7 \\
& & $2019-2020$ & 3 \\
& & Universitas & 1 \\
2 & Jenjang & SMA dan SMK & 3 \\
& Pendidikan & SMP & 12 \\
& Ukuran & 30 atau kurang & 6 \\
3 & Sampel & 31 atau lebih & 10 \\
& Sumber & Jurnal & 15 \\
4 & Publikasi & Prosiding & 1 \\
\hline
\end{tabular}

\section{Statistical Analysis}

Unit analisis dalam meta-analisis adalah ukuran efek (Glass, 2015). Ukuran efek dalam penelitian ini adalah indeks yang menggambarkan besarnya pengaruh PBL terhadap kemampuan literasi matematis siswa. Prosedur statistik dalam penelitian ini didasarkan pada penjelasan Borenstein et al. (2009) yaitu (a) menghitung ukuran efek tiap studi primer; (b) melakukan uji heterogenitas dan pemilihan model estimasi; (c) memeriksa bias publikasi; dan (d) menghitung nilai-p untuk menguji hipotesis penelitian. Analisis terhadap alasan adanya variasi ukuran efek yaitu dengan memeriksa hubungan natra variabel mediator, dilakukan setelah diketahui model yang diestimasi adalah efek-acak (Haidich, 2010). Aplikasi yang membantu analisis data adalah program Comprehensive MetaAnalysis (CMA). Persamaan Cohen'd menjadi estimasi yang baik terhadap populasi, namun menjadi bias terhadap studi yang memuat sampel kecil. Mempertimbangkan variasi ukuran sampel antar studi maka penelitian ini menggunakan persamaan Hedge's g untuk menentukan indeks ukuran efek. Interpretasi ukuran efek, menggunakan Cohen (Sullivan \& Feinn, 2012) yaitu: ukuran efek kurang dari 0,2 (efek kecil), ukuran efek diantara 0,2 dan 0,5 (efek sedang), ukuran efek diantara 0,8 , dan 1,3 (efek besar), dan ukuran efek di atas 1,3 (efek sangat besar).

Uji heterogenitas dilakukan dengan memeriksa statistic $\mathrm{Q}$ dan nilai p. Jika nilai $\mathrm{p}<0,05$ maka hipotesis nol yang menyatakan bahwa ukuran efek tiap studi homogen ditolak. Dengan demikian estimasi yang dipilih adalah model efek-acak. Jika nilai $\mathrm{p}>0,05$ maka hipotesis nol diterima dan model efek-tetap dievaluasi. Analisis terhadap tingkat variasi studi dengan memeriksa variable moderator dilakukan setelah ditentukan bahwa estimasi yang dipilih adalah model efek-acak.

Pemeriksaan terhadap bias publikasi dilakukan untuk mencegah representasi yang salah terhadap temuan. Studi yang telah diterbitkan lebih mungkin untuk dimasukkan dalam meta-analisis daripada rekan mereka yang tidak dipublikasikan, dan ini menyebabkan kekhawatiran bahwa meta-analisis mungkin melebihlebihkan ukuran efek sebenarnya (Borenstein et al., 2009; Tamur, Jehadus, Nendi, et al., 2020). Untuk mengantisipasi hal ini maka plot corong diperiksa untuk menilai kemungkinan jumlah bias, dan statistic Rosenthal's FSN (Tamur, Juandi, \& Kusumah, 2020) digunakan untuk menilai dampak bias. Penelitian ini dikatakan tahan terhadap bias jika penyebaran ukuran efek menunjukkan distribusi yang simetris di sekitar garis vertikal (Borenstein, Hedges, \& Rothstein, 2009). Jika ukuran efek tidak sepenuhnya tersebar simetris maka statistik gagal-aman N (FSN) Rosenthal 
digunakan. Jika nilai FSN / $(5 \mathrm{k}+10)>$ 1 dengan $\mathrm{k}$ adalah jumlah studi yang dimasukkan dalam meta-analisis maka penelitian ini tahan terhadap bias publikasi (Mullen et al., 2001).

\section{HASIL DAN PEMBAHASAN}

Tujuan pertama dari penelitian ini adalah untuk mengetahui efek keseluruhan modep PBL terhadap kemampuan literasi matematika siswa. Tahap pertama analisis adalah menghitung ukuran efek tiap studi primer. Berdasarkan perhitungan keseluruhan, ukuran efek dari masingmasing studi disajikan pada Tabel 3.

Tabel 3. Transformasi ukuran efek tiap studi.

\begin{tabular}{clcccc}
\hline No & \multicolumn{1}{c}{ Author } & Effect Size & $\begin{array}{c}\text { Standard } \\
\text { Error }\end{array}$ & $\begin{array}{c}\text { Lower } \\
\text { Limit }\end{array}$ & $\begin{array}{c}\text { Upper } \\
\text { Limit }\end{array}$ \\
\hline 1 & Budiono, 2014 & 0.731 & 0.288 & 0.167 & 1.295 \\
2 & Dewi dkk a, 2015 & 1.283 & 0.274 & 0.746 & 1.820 \\
3 & Dewi dkk b, 2015 & 0.537 & 0.253 & 0.040 & 1.033 \\
4 & Istiandaru, dkk, 2015 & 2.001 & 0.336 & 1.342 & 2.660 \\
5 & Kusuma a, 2017 & 0.669 & 0.277 & 0.125 & 1.213 \\
6 & Kusuma b, 2017 & 0.570 & 0.277 & 0.027 & 1.114 \\
7 & Nolaputra dkk, 2018 & 0.057 & 0.264 & -0.459 & 0.574 \\
8 & Endramawati dkk, 2019 & 0.482 & 0.283 & -0.072 & 1.035 \\
9 & Hairunnisah dkk, 2019 & 0.851 & 0.253 & 0.356 & 1.346 \\
10 & Astuti, 2020 & 0.582 & 0.250 & 0.091 & 1.073 \\
11 & Sriwahyuni dkk, 2018 & 1.188 & 0.268 & 0.662 & 1.714 \\
12 & Aula dkk, 2019 & 0.481 & 0.242 & 0.007 & 0.954 \\
13 & Yustitia, 2019 & 2.059 & 0.296 & 1.479 & 2.638 \\
14 & Priyonggo dkk, 2019 & 1.439 & 0.272 & 0.906 & 1.971 \\
15 & Imam dkk, 2020 & 0.649 & 0.239 & 0.180 & 1.118 \\
16 & Dewi \& Listyani, 2018 & -0.037 & 0.247 & -0.521 & 0.447 \\
\hline
\end{tabular}

Berdasarkan Tabel 3, rentang keseluruhan ukuran efek adalah -0,037 hingga 2,059, dengan tingkat kepercayaan 95\%. Mengacu pada klasifikasi, dapat diperiksa bahwa lima ukuran efek memiliki efek positif yang besar, $(n=5)$; tiga ukuran efek memiliki efek sangat besar $(n=3)$; enam ukuran efek memiliki efek sedang $(n=6)$; dan dua ukuran efek memiliki efek kecil (n =2). Terdapat dua studi (nomor 7 dan 12) yang melaporkan efek nol artinya PBL tidak lebih baik dari metode pembelajaran konvensional. Tabel 4 menunjukkan perbandingan hasil metaanalisis menurut model efek. Seperti yang diilustrasikan pada Tabel 4, tampak bahwa menurut model efek tetap, batas bawah interval kepercayaan
95\% adalah 0,654 , dan batas atas adalah 0,916 . Ukuran efek keseluruhan studi adalah 0,785 . Ukuran efek ini diterima sebagai efek besar.

Tahap kedua adalah melakukan uji heterogenitas dan pemilihan model estimasi. Berdasarkan Tabel 4 nilai nilai $\mathrm{Qb}$ adalah 67.234 dan nilai $\mathrm{p}$ adalah 0,000. Dengan demikian, distribusi ukuran efek ditemukan heterogen pada $\mathrm{p}<0,05$ (ukuran efek aktual bervariasi dari satu studi ke studi lainnya). Tingkat variasi ukuran efek antar studi tersebut tercermin dari nilai I-squared yaitu 77,690 yang menunjukkan bahwa $77 \%$ varian dalam ukuran efek yang diamati mencerminkan persentase variabilitas yang disebabkan oleh heterogenitas 
DOI: https://doi.org/10.24127/ajpm.v9i4.3049

yang sebenarnya (bukan disebabkan oleh kesalahan pengambilan sampel). Dengan demikian penelitian ini memiliki heterogenitas yang tinggi karena nilai I-squared $\geq 75 \%$ (Mullen et al., 2001). Karena hasil uji homogenitas ditolak, maka model estimasi yang digunakan adalah model efek-acak.

Tahap ketiga adalah memeriksa bias publikasi. Gambar 1 menyajikan plot corong penelitian.

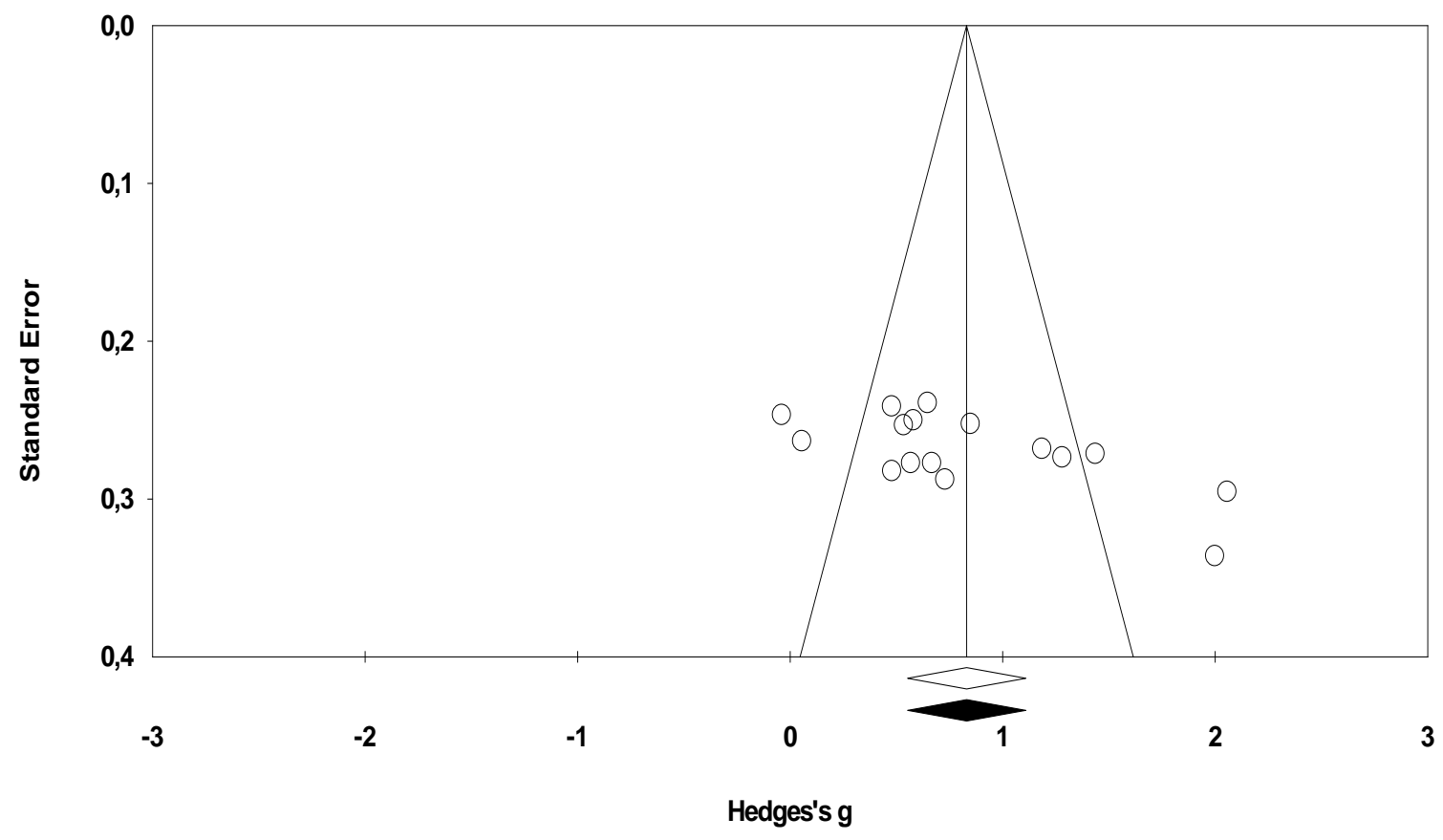

Gambar 1. Plot Corong Penelitian

Berdasarkan Gambar 1 tampak bahwa penyebaran ukuran efek tidak sepenuhnya simetris disekitar garis vertikal. Karena itu nilai statistik gagalaman N (FSN) Rosenthal diperiksa. Berdasarkan perhitungan menggunakan CMA, nilai $\mathrm{N}$ dihitung sebesar 682 .
Hasil perhitungan dari $682 /(5 * 16+$ 10 ), adalah $5,246>1$. Artinya, studi yang termasuk dalam analisis ini tahan terhadap bias publikasi. Dengan demikian, tidak ada studi yang hilang atau perlu ditambahkan dalam analisis sebagai akibat dari bias publikasi.

Tabel 4. Perbandingan Hasil Berdasarkan Model Estimasi

\begin{tabular}{|c|c|c|c|c|c|c|c|c|c|c|c|}
\hline \multirow[b]{2}{*}{ No } & \multirow[b]{2}{*}{$\begin{array}{c}\text { Model } \\
\text { Estimasi }\end{array}$} & \multirow[b]{2}{*}{$\mathbf{n}$} & \multirow[b]{2}{*}{$\mathbf{Z}$} & \multirow[b]{2}{*}{$\mathbf{p}$} & \multirow[b]{2}{*}{$\begin{array}{l}\text { Effect } \\
\text { Size }\end{array}$} & \multirow[b]{2}{*}{$\begin{array}{c}\text { Standard } \\
\text { Error }\end{array}$} & \multicolumn{2}{|c|}{$95 \% \mathrm{CL}$} & \multirow[b]{2}{*}{$Q_{b}$} & \multirow[b]{2}{*}{$\begin{array}{c}\text { P- } \\
\text { value }\end{array}$} & \multirow[b]{2}{*}{$\begin{array}{c}\text { I- } \\
\text { squared }\end{array}$} \\
\hline & & & & & & & $\begin{array}{l}\text { Lower } \\
\text { Limit }\end{array}$ & $\begin{array}{l}\text { Upper } \\
\text { Limit }\end{array}$ & & & \\
\hline 1 & Efek-Tetap & 16 & 11.758 & 0.000 & 0.785 & 0.067 & 0.654 & 0.916 & \multirow{2}{*}{67.234} & \multirow{2}{*}{0.000} & \multirow[b]{2}{*}{77,690} \\
\hline 2 & Efek-Acak & 16 & 5.855 & 0.000 & 0.830 & 0.142 & 0.552 & 1.108 & & & \\
\hline
\end{tabular}

Tahap terakhir adalah menghitung nilai-p untuk menguji hipotesis penelitian. Tabel 4 membandingkan hasil analisis sesuai model estimasi. Seperti yang telah disajikan pada Tabel 4, bahwa menurut 
model efek acak, interval kepercayaan 95\% berkisar antara 0,552 hingga 1,108 yang menunjukkan bahwa perbedaan rata-rata dapat jatuh di mana saja dalam kisaran ini, dan ukuran efek keseluruhan studi adalah 0,830. Ukuran efek ini diterima sebagai efek besar. Sebagai hasil dari penghitungan uji $\mathrm{Z}$ untuk menentukan signifikansi statistik, skor $\mathrm{z}$ ditemukan sebesar 5,855. Hasil ini dapat dikatakan signifikan secara statistik pada taraf $\mathrm{p}<0,001$. Dengan demikian, penerapan PBL memiliki pengaruh yang positif yang besar terhadap kemampuan literasi matematis siswa daripada pendekatan konvensional.

Terakhir, analisis tingkat variasi studi dengan memeriksa pengaruh moderator diujicobakan pada 16 ukuran efek dari 14 penelitian primer yaitu tahun penelitian, tingkat pendidikan, ukuran sampel, dan sumber publikasi. Nilai hedges-g, interval kepercayaan $95 \%, \mathrm{Z}$, dan $\mathrm{p}$ dihitung menggunaan CMA dan disajikan pada Tabel 5.

Tabel 5. Ringkasan hasil analisis moderator.

\begin{tabular}{|c|c|c|c|c|c|c|c|c|c|}
\hline \multirow[b]{2}{*}{ No } & \multirow[b]{2}{*}{$\begin{array}{l}\text { Variabel } \\
\text { Mediator }\end{array}$} & \multirow[b]{2}{*}{ Kelompok } & \multirow[b]{2}{*}{$\mathbf{n}$} & \multirow{2}{*}{$\begin{array}{c}\text { Ukuran } \\
\text { Efek } \\
\text { gabungan } \\
\text { (Hedge's g) }\end{array}$} & \multicolumn{2}{|c|}{$\begin{array}{c}\text { Test of null } \\
\text { (2-Tail) }\end{array}$} & \multicolumn{3}{|c|}{ Heterogeneity } \\
\hline & & & & & $\mathbf{Z}$ & $\mathbf{p}$ & $\begin{array}{c}\text { Between- } \\
\text { Classes } \\
\text { Effect } \\
\left(Q_{b}\right)\end{array}$ & $\begin{array}{l}\text { Df } \\
(\mathbf{Q})\end{array}$ & $\mathbf{P}$ \\
\hline \multirow{4}{*}{1} & & 2013-2014 & 4 & 1.115 & 3.606 & 0.000 & \multirow{4}{*}{5.962} & \multirow{4}{*}{3} & \multirow{4}{*}{0.113} \\
\hline & Tahun & $2015-2016$ & 2 & 0.620 & 3.159 & 0.002 & & & \\
\hline & Penelitian & 2017-2018 & 7 & 0.512 & 3.203 & 0.001 & & & \\
\hline & & 2019-2020 & 3 & 1.368 & 3.313 & 0.001 & & & \\
\hline \multirow{3}{*}{2} & \multirow{3}{*}{$\begin{array}{l}\text { Jenjang } \\
\text { Pendidikan }\end{array}$} & Universitas & 1 & 2.059 & 6.964 & 0.000 & \multirow{3}{*}{16.571} & \multirow{3}{*}{2} & \multirow{3}{*}{0.000} \\
\hline & & SMA dan SMK & 3 & 0.854 & 2.974 & 0.003 & & & \\
\hline & & SMP & 12 & 0.723 & 4.934 & 0.000 & & & \\
\hline \multirow[b]{2}{*}{3} & Ukuran & 30 or less & 6 & 0.730 & 3.001 & 0.003 & \multirow{2}{*}{0.277} & \multirow{2}{*}{1} & \multirow{2}{*}{0.599} \\
\hline & Sampel & 31 atau lebih & 10 & 0.889 & 4.918 & 0.000 & & & \\
\hline \multirow[b]{2}{*}{4} & Sumber & Jurnal & 15 & 0.882 & 6.195 & 0.000 & \multirow{2}{*}{7.571} & \multirow{2}{*}{1} & \multirow{2}{*}{0.006} \\
\hline & Publikasi & Prosiding & 1 & 0.057 & 0.218 & 0.827 & & & \\
\hline
\end{tabular}

\section{Tahun Penelitian}

Variabel moderator berdasarkan tahun penelitian menemukan bahwa penelitian yang dilakukan dari tahun 2013 hingga 2014 memiliki ukuran efek 1,115 (efek sangat besar) dalam kategori yang sama dengan ukuran efek pada penelitian antara tahun 2019 dan 2020 memiliki ukuran efek sebesar 1,368 (efek sangat besar). Tahun penelitian 2015 sampai 2016 mempunyai ukuran pengaruh sebesar 0,620 (pengaruh sedang) yang berada pada kategori yang sama dengan tahun penelitian 2017 sampai 2018 yang mempunyai ukuran pengaruh sebesar 0,512 (pengaruh sedang). Niai $Q$ ditemukan sebesar 5,962 dan $\mathrm{p}>0,05$. Hal ini berarti tidak ada perbedaan ukuran efek rata-rata antar kelompok tahun.

\section{Jenjang Pendidikan}

Menurut hasil analisis yang diberikan pada Tabel 5, ukuran efek dalam studi yang dilakukan di sekolah menengah pertama (SMP) 0,723 (efek besar) tidak jauh berbeda dari ukuran 
efek dalam studi yang dilakukan di sekolah menengah atas dan sekolah menengah kejuruan (SMA dan SMK) sebesar 0,854 (efek besar). Namun keduanya memiliki efek yang sangat berbeda dengan yang dilakukan di universitas, yaitu 2.059 (efek yang sangat besar). Hasil uji heterogenitas menunjukkan bahwa ukuran efek ratarata antar jenjang Pendidikan berbeda $(\mathrm{Q}=16,571$ dan $\mathrm{p}<0,05)$. Dapat dikatakan bahwa penerapan PBL terhadap kemampuan literasi matematika sangat efektif dan berpengaruh di tingkat universitas dibandingkan di tingkat SMP dan SMA / SMK.

\section{Ukuran Sampel}

Berdasarkan ukuran sampel ditemukan bahwa penelitian dengan rentang 1-30 siswa memiliki ukuran efek 0,730 (efek besar) dalam kategori yang sama dengan studi dengan rentang 31 siswa atau lebih 0,889 (efek besar). Hasil uji heterogenitas menunjukkan bahwa ukuran efek rata-rata kedua kelompok studi tidak berbeda $(\mathrm{Q}=0,277$ dan $\mathrm{p}>0,05)$. Dengan demikian perbedaan ukuran sampel penelitian tidak mengubah ukuran efek studi yang membandingkan penerapan PBL dan konvensional terhadap kemampuan literasi matematis siswa.

\section{Sumber Publikasi}

Berdasarkan sumber publikasi diketahui bahwa besarnya pengaruh pada penelitian yang dipublikasikan dalam jurnal sebesar 0,882 (pengaruh besar) dan besar pengaruh pada penelitian yang dipublikasikan dalam prosiding adalah 0,057 (pengaruh kecil). Hasil uji heterogenitas menunjukkan bahwa ukuran efek rata-rata dari kedua kelompok studi berbeda $(\mathrm{Q}=7,571$ dan $\mathrm{p}<0,05)$.
Hasil analisis menunjukkan bahwa ukuran efek keseluruhan dari studi yaitu 0,830 menunjukkan bahwa pembelajaran yang menerapkan PBL memiliki efek positif yang besar terhadap kemampuan literasi matematis siswa jika dibandingkan dengan pembelajaran konvesional. Ukuran efek tersebut menunjukkan bahwa rata-rata siswa yang terpapar PBL melebihi kemampuan literasi matematis sebesar $79 \%$ siswa di kelas konvesional yang awalnya setara. Temuan ini juga dapat diinterpretasikan bahwa, siswa bergeser dari persentil ke-50 ke persentil ke-79 dalam kemampuan literasi matematis ketika PBL diterapkan. Temuan ini juga mengungkap sejauh mana jarak kedua kelompok menggunakan interpretasi Coe (2002) yaitu rata-rata siswa yang menduduku peringkat ke-13 dalam grup ekperimen, setara dengan mereka yang berada di peringkat ke-6 dalam kelompok kontrol.

Temuan ini sejalan dengan hasil meta-analisis sebelumnya yang telah dilakukan oleh Gijbels et al. (2005), dan Rosli et al. (2014) dengan masingmasing ukuran efek keseluruhan studi adalah 0,748 dan 0,830. Namun hasil yang berbeda ditemukan oleh Demirel \& Dağyar (2016) dan Dochy et al., (2003) dengan masing-masing ukuran efek keseluruhan studi yaitu 0,440 dan 0,390. Perbedaan hasil ini menjadi ide dasar untuk penelitian selanjutnya dengan melibatkan studi primer yang lebih banyak, dan kriteria inklusi yang diperluas.

Berdasarkan tahun penelitian menunjukkan bahwa penelitian yang dilakukan pada periode tahun terakhir memiliki effect size yang relatif lebih besar dibandingkan dengan tiga periode lainnya. Namun tidak mengubah homogenitas ukuran efek rata rata antar kelompok studi. Temuan ini didukung 
oleh meta-analisis sebelumnya (Tamur, Juandi, \& Adem, 2020) yang menyelidiki variasi hasil studi primer berdasarkan tahun penelitian.

Berdasarkan jenjang pendidikan terlihat bahwa ukuran efek semakin meningkat dari jenjang pendidikan terendah hingga tertinggi. Hal ini diilustrasikan oleh besarnya efek JHS, SHS dan VHS dan universitas masingmasing sebesar 0,723; 0,854; dan 2.059 . Hal ini menandakan bahwa semakin tinggi jenjang pendidikan dimana model PBL diterapkan maka tingkat efektifitasnya semakin tinggi terhadap kemampuan literasi matematis siswa. Hal ini sejalan dengan temuan Ahlfeldt et al. (2005) dan Tamur et al. (2020) bahwa kelas yang lebih tinggi memiliki tingkat keterlibatan yang lebih tinggi, dan tingkat kelas, tahun pendaftaran, dan tingkat PBL sangat mempengaruhi ukuran efek. Dengan demikian dapat dikatakan bahwa untuk mencapai tingkat efektivitas yang lebih tinggi, PBL disarankan diberikan di perguruan tinggi.

Berdasarkan ukuran sampel, hasil yang diperoleh cukup mengejutkan karena berbeda dengan asumsi kami bahwa model PBL yang diterapkan pada kelompok kecil akan lebih efektif daripada yang diterapkan pada kelompok besar. Dalam hal ukuran sampel, hasil ini berbeda dengan temuan Tamur et al. (2020), bahwa ukuran sampel yang kecil memiliki ukuran efek yang lebih besar daripada ukuran sampel yang besar. Namun studi lainnya mendukung temuan ini (misalnya; Demirel \& Dağyar, 2016 dan Susanti, Juandi \& Tamur, 2020). Untuk mencapai hasil yang konsisten maka perlu melibatkan studi primer yang lebih banyak dalam analisis.

Selanjutnya, variabel moderator dalam hal sumber publikasi terlihat terdapat perbedaan yang sangat signifikan antara jurnal dan prosiding pada pembelajaran PBL terhadap kemampuan literasi matematika. Namun, temuan tentang ukuran sampel berbeda dari asumsi kami bahwa ukuran efek berdasarkan sumber publikasi tidak berbeda. Temuan bahwa ukuran efek pada jurnal 0,882 lebih besar dari prosiding 0,057 menunjukkan bahwa terdapat kecenderungan jurnal hanya mempublikasikan makalah atau hasil penelitian yang signifikan. Akan tetapi, hasil ini bersifat tentatif karena jumlah kelompok studi yang diterbitkan melalui prosiding hanya satu. Oleh karena itu studi meta-analisis lebih lanjut diperlukan dengan mempertimbangkan lebih banyak data empiris dari publikasi prosiding untuk memverifikasi temuan.

\section{KESIMPULAN DAN SARAN}

Hasil analisis menunjukkan bahwa penerapan PBL memberikan dampak positif yang besar terhadap kemampuan literasi matematika siswa dibandingkan dengan penerapan pendekatan konvensional. Berdasarkan analisis moderator terungkap bahwa perbedaan jenjang pendidikan dan sumber publikasi dapat mengubah ukuran efek studi.

Walaupun temuan penelitian ini menunjukkan bahwa penerapan PBL memiliki pengaruh yang besar terhadap kemampuan literasi matematis siswa, temuan tersebut hanya berdasarkan penelitian pada 14 studi primer. Ada juga studi terkait lainnya yang tidak dapat dievaluasi karena pengetahuan metodologis yang diperlukan tidak memadai. Oleh karena itu, disarankan untuk melakukan penelitian kedepannya dengan melakukan pendataan lebih lanjut untuk mendapatkan variabel yang diperlukan. 
DOI: https://doi.org/10.24127/ajpm.v9i4.3049

\section{DAFTAR PUSTAKA}

Ahlfeldt, S., Mehta, S., \& Sellnow, T. (2005). Measurement and analysis of student engagement in university classes where varying levels of PBL methods of instruction are in use. Higher Education Research and Development, 24(1), 5-20. https://doi.org/10.1080/072943605 2000318541

Akinoğlu, O., \& Tandoğan, R. Ö. (2007). The effects of problembased active learning in science education on students' academic achievement, attitude and concept learning. Eurasia Journal of Mathematics, Science and Technology Education, 3(1), 7181.

https://doi.org/10.12973/ejmste/75 375

Anugraheni, I. (2018). Meta Analisis Model Pembelajaran Problem Based Learning dalam Meningkatkan Keterampilan Berpikir Kritis di Sekolah Dasar. Polygot, 14(1), 9-18. http://dx.doi.org/10.19166/pji.v14i 1.789

Asror, A. H. (2016). Meta-Analisis : PBL. PRISMA Prosiding Seminar Nasional Matematika, 508-513. https://journal.unnes.ac.id/sju/inde x.php/prisma/article/download/216 82/10309

Astuti, A. D. K. P. (2020). Pengaruh Problem Based Learning Terhadap Kemampuan Literasi Matematis Siswa Kelas VII Di SMP Negeri 1 Bobotsari. Journal of Mathematics Education, 4(32), 37-46.

Aula, M. F. R., Suyitno, H., \& Rosyida, I. (2019). Mathematical Literacy
Ability Viewed From Student' $\mathrm{s}$ Learning Style Based on Gender Differences on PBL Assistance Project Assessment. Unnes Journal of Mathematics Education Research Http://Journal.Unnes.Ac.Id/Sju/Ind ex.Php/Ujmer, 8(9), 96-103.

Bolstad, O. H. (2020). Secondary teachers , operationalisation of mathematical literacy. European Journal of Science and Mathematics Education, 8(3), 115135.

Borenstein, M., Hedges, L. V, Higgins, J. P. T., \& Rothstein, H. R. (2009). Introduction to Meta-Analysis (Issue January). A John Wiley and Sons, Ltd., Publication. https://doi.org/10.1002/978047074 3386

Borenstein, M., Hedges, L. V, \& Rothstein, H. R. (2009). Introductionto Meta-Analysis (Issue January). John Wiley \& Sons.

Coe, R. (2002). It' s the Effect Size, Stupid. In Educational Research (Issue September, pp. 1-18).

Demirel, M., \& Dağyar, M. (2016). Effects of Problem-Based Learning on Attitude: A Meta-analysis Stud. EURASIA Journal of Mathematics, Science \& Technology Education, 12(8), 2115-2137. https://doi.org/10.12973/eurasia.20 16.1293a

Dewi, H. A., \& Listyani, E. (2018). Perbandingan keefektifan pendekatan problem posing dan problem-based learning ditinjau dari kemampuan literasi matematis siswa SMP Kelas VIII. Universitas Negeri Yogyakarta. 
Dochy, F., Segers, M., Van den Bossche, P., \& Gijbels, D. (2003). Effects of problem-based learning: A meta-analysis. Learning and Instruction, 13(5), 533-568. https://doi.org/10.1016/S09594752(02)00025-7

Franzen, M. (2020). Meta-analysis. In H. V. Zeigler \& T. . Shackelford (Eds.), Encyclopedia of Personality and Individual Differences (p. 5925). Springer, Cham. https://doi.org/10.1007/9783-319-24612-3_1326

Freeman-Green, S. M., O'Brien, C., Wood, C. L., \& Hitt, S. B. (2015). Effects of the SOLVE strategy on the mathematical problem solving skills of secondary students with learning disabilities. Learning Disabilities Research and Practice, 30(2), 76-90. https://doi.org/10.1111/ldrp.12054

Genc, M., \& Erbas, A. K. (2019). Secondary mathematics teachers' conceptions of mathematical literacy. International Journal of Education in Mathematics, Science and Technology, 7(3), 222-237.

Gijbels, D., Dochy, F., Van Den Bossche, P., \& Segers, M. (2005). Effects of problem-based learning: A meta-analysis from the angle of assessment. Review of Educational Research, 75(1), 27-61. https://doi.org/10.3102/003465430 75001027

Glass, G. V. (2015). Meta-analysis at middle age: A personal history. Research Synthesis Methods, 6(3), 221-231.

https://doi.org/10.1002/jrsm.1133
Haidich, A. B. (2010). Meta-analysis in Medical Research. Hippokratia, 14(Supp 1), 29-37. https://pubmed.ncbi.nlm.nih.gov/2 1487488/

Higgins, S., \& Katsipataki, M. (2015). Evidence from meta-analysis about parental involvement in education which supports their children's learning. Journal of Children's Services, 10(3), 280-290. https://doi.org/10.1108/JCS-022015-0009

Istiandaru, A., Istihapsari, V., Wardono, \& Mulyono. (2015). Problem Based Learning (PBL) dengan Pendekatan Realistik-Saintifik dan Asesmen PISA untuk Meningkatkan Kemampuan Literasi Matematika. Edumatica, 5(1), 1-11. https://onlinejournal.unja.ac.id/index.php/eduma tica/article/view/2670

Mullen, B., Muellerleile, P., \& Bryant, B. (2001). Cumulative metaanalysis: A consideration of indicators of sufficiency and stability. Personality and Social Psychology Bulletin, 27(11), 14501462.

https://doi.org/10.1177/014616720 12711006

OECD. (2019). PISA 2018 insights and interpretations. In OECD Publishing.

https://www.oecd.org/pisa/PISA 2018 Insights and Interpretations FINAL PDF.pdf

Pradana, L. N., Sholikhah, O. H., Maharani, S., \& Kholid, M. N. (2020). Virtual mathematics kits (VMK): Connecting digital media to mathematical literacy. International Journal of Emerging 
DOI: https://doi.org/10.24127/ajpm.v9i4.3049

Technologies in Learning, 3, 234241.

https://doi.org/10.3991/ijet.v15i03. 11674

Priyonggo, H. W., Wardono, W., \& ... (2019). Mathematics Literacy Skill on Problem Based Learning Assisted by E-Module Agito Based on Learning Motivation. ... Journal of Mathematics ..., 10(1), 55-59.

https://journal.unnes.ac.id/sju/inde x.php/ujmer/article/view/34610

Qin, Y., Wang, Y., \& Floden, R. E. (2016). The Effect of ProblemBased Learning on Improvement of the Medical Educational Environment: A Systematic Review and Meta-Analysis. Medical Principles and Practice, 25(6), 525-532. https://doi.org/10.1159/000449036

Rosli, R., Capraro, M. M., \& Capraro, R. M. (2014). The effects of problem posing on student mathematical learning: A metaanalysis. International Education Studies, 7(13), 227-241. https://doi.org/10.5539/ies.v7n13p 227

Schmidt, F. L., \& Hunter, J. E. (2015). Methods of Meta-Analysis: Correcting Error and Bias in Research Findings (Third). 55 City Road, London: SAGE Publications, Ltd. https://doi.org/10.4135/978148339 8105

Sriwahyuni, A., Rahmatudin, J., \& Hidayat, R. (2018). Penerapan Model Pembelajaran Problem Based Learning Untuk Meningkatkan Kemampuan Literasi dan Disposisi Matematis
Siswa SMP. Journal Integral, 9(2), 58-68.

Sullivan, G. M., \& Feinn, R. (2012). Using Effect Size - or Why the P Value Is Not Enough . Journal of Graduate Medical Education, 4(3), 279-282.

https://doi.org/10.4300/jgme-d-1200156.1

Susanti, N., Juandi, D., \& Tamur, M. (2020). The Effect of ProblemBased Learning ( PBL ) Model On Mathematical Communication Skills of Junior High School Students - A Meta-Analysis Study. JTAM (Jurnal Teori Dan Aplikasi Matematika), 4(2), 145-154.

Tamur, M, Jehadus, E., Nendi, F., Mandur, K., \& Murni, V. (2020). Assessing the effectiveness of the contextual teaching and learning model on students 'mathematical understanding ability: a metaanalysis study. Journal of Physics: Conference Series, 1657(1), 012067.

https://doi.org/10.1088/17426596/1657/1/012067

Tamur, Maximus. (2017). Pembelajaran Berbasis Software Matematika Sebagai Upaya Mengembangkan Kemampuan Literasi Matematis Siswa. Seminar Nasional Pendidikan Matematika, 1(1), 8292.

Tamur, Maximus, \& Juandi, D. (2020). Effectiveness of Constructivism Based Learning Models Against Students Mathematical Creative Thinking Abilities in Indonesia: A Meta-Analysis Study. Mathematics, Science, and Computer Science Education International Seminar, MSCEIS 
DOI: https://doi.org/10.24127/ajpm.v9i4.3049

2019 ,

$1-8$.

https://doi.org/10.4108/eai.12-10-

2019.2296507

Tamur, Maximus, Juandi, D., \& Adem, A. M. G. (2020). Realistic Mathematics Education in Indonesia and Recommendations for Future Implementation: A Meta-Analysis Study. Jurnal Teori Dan Aplikasi Matematika, 4(1), 17-27.

https://doi.org/10.31764/jtam.v4i1. 1786

Tamur, Maximus, Juandi, D., \& Kusumah, Y. S. (2020). The Effectiveness of the Application of Mathematical Software in Indonesia: A Meta-Analysis Study. International Journal of Instruction, 13(4), 867-884. https://doi.org/10.29333/iji.2020.1 $3453 \mathrm{a}$
Wicaksono, M. A., \& Agustyaningrum, N. (2018). Efektifitas Pendekatan CTL dan PBL dengan Setting Kooperatif Tipe STAD ditinjau dari Kemampuan Literasi Matematis Siswa. Cahaya Pendidikan, 4(1), 23-35.

Yanto, F., Festiyed, F., Iswri, M., \& Enjoni, E. (2019). Meta-Analysis: Improving Creativity through Assessment in a Problem-Based Learning Environment. 178(ICoIE 2018), 23-26. https://doi.org/10.2991/icoie18.2019.6 